\title{
Path analysis of phosphorus activation capacity as induced by low-molecular-weight organic acids in a black soil of Northeast China
}

\author{
Xiaoyan Yang ${ }^{1,2} \cdot$ Xiangwei Chen $^{2} \cdot$ Erhui Guo $^{1} \cdot$ Xitian Yang $^{1}$ \\ Received: 10 January 2018 / Accepted: 16 May 2018 / Published online: 8 June 2018 \\ (C) The Author(s) 2018
}

\begin{abstract}
Purpose The present study was designed to assess the potential effects of low-molecular-weight organic acids on the activation of inorganic phosphorus, obtain exact information on the acidity effect of proton and complex effect of organic anion in P availability, and determine the components among phosphorus fractions that contributed the most to inorganic phosphorus activation in black soil.

Materials and methods Both oxalic and citric acids treated with different concentrations and $\mathrm{pH}$ values were carefully selected. The activating amounts of total inorganic phosphorus and individual phosphorus fractions were estimated. Path analysis was used to analyze the direct and indirect effects on inorganic phosphorus activation.

Results and discussion The amount of total activating- $P_{i}$ increased as the concentrations of oxalic and citric acids increased. When the concentrations were $\leq 1.0 \mathrm{mmol} \mathrm{L}^{-1}$, oxalic acid exhibited a lower capability than citric acid in total activating- $\mathrm{P}_{\mathrm{i}}$, but when the concentrations were $\geq 1.5 \mathrm{mmol} \mathrm{L}^{-1}$, oxalic acid exhibited a higher capability. The amount of total activating- $\mathrm{P}_{\mathrm{i}}$ decreased as $\mathrm{pH}$ of LMWOAs increased. LMWOAs-induced $\mathrm{P}_{\mathrm{i}}$ activation might be attributed to combine acidity and complex effects.

Conclusions Correlation analysis showed that the activation of total $\mathrm{P}_{\mathrm{i}}$ was significantly correlated with the activation of $\mathrm{H}_{2} \mathrm{O}-\mathrm{P}_{\mathrm{i}}$, $\mathrm{NaHCO}_{3}-\mathrm{P}_{\mathrm{i}}, \mathrm{NaOH}-\mathrm{P}_{\mathrm{i}}$, and $\mathrm{HCl}-\mathrm{P}_{\mathrm{i}}(p<0.05)$. Path analysis revealed that soil activating- $\mathrm{H}_{2} \mathrm{O}-\mathrm{P}_{\mathrm{i}}$ mainly affected $\mathrm{P}_{\mathrm{i}}$ activation through an indirect path. The contribution of activating- $\mathrm{NaHCO}_{3}-\mathrm{P}_{\mathrm{i}}$ alone was maximal on the total activating- $\mathrm{P}_{\mathrm{i}}$ by both the direct and indirect effects, followed by activating- $\mathrm{NaOH}-\mathrm{P}_{\mathrm{i}}$ and activating-HCl- $\mathrm{P}_{\mathrm{i}}$.
\end{abstract}

Keywords Acidity effect $\cdot$ Complex effect $\cdot$ Path analysis $\cdot$ Phosphorus activation $\cdot$ Phosphorus fractions

\section{Introduction}

The macronutrient phosphorus $(\mathrm{P})$ is essential for plant growth. As a result of low $\mathrm{P}$ contents and the strong binding

Responsible editor: Yuan Ge

Electronic supplementary material The online version of this article (https://doi.org/10.1007/s11368-018-2034-z) contains supplementary material, which is available to authorized users.

Xitian Yang

xitianyang@aliyun.com

1 School of Forestry, Henan Agricultural University, Zhengzhou 450000, Henan, China

2 School of Forestry, Northeast Forestry University, Harbin 150040, Heilongjiang, China of phosphate to iron $(\mathrm{Fe})$ and aluminum $(\mathrm{Al})$ oxide forms that are largely unavailable for plant uptake in the short term, most soils are unable to supply $\mathrm{P}$ to plants at sufficient rates for sustaining optimal growth; consequently, $\mathrm{P}$ availability is often a growth-limiting factor (Wang et al. 2017; Bauke et al. 2017). $P$ fertilizers are often applied to avoid $P$ deficiency in plants (Duminda et al. 2017), but these applications have increased the accompanying risk of $\mathrm{P}$ losses to ground and surface waters, contributing to eutrophication (Fischer et al. 2017). Moreover, $P$ in soil exists predominantly in inorganic fractions that are either adsorbed into soil mineral surfaces or occasionally appear as available precipitates (Cao et al. 2015). There is therefore an increasing need for alternative, sustainable methods that facilitate plant acquisition of $P$ from legacy $\mathrm{P}$ pools. In studies focusing on $\mathrm{P}$ availability, the lowmolecular-weight organic acids (LMWOAs) have been suggested to be the most important molecules exuded by plants 
and mycorrhizae (Clarholm et al. 2015). However, there are also researchers who believe that organic acids exert an inhibitory effect or no effect on the availability of P. For example, Iyamuremye and Dick (1996) found that only citric acid showed a significant effect. In addition, the effects of various organic acids on $\mathrm{P}$ activation were also different significantly, and different researchers had drawn different conclusions (Strom et al. 2005; Gong et al. 2010; Khademi et al. 2010; Lv et al. 2015; Menezes-Blackburn et al. 2016). Furthermore, the solubility of P-bearing minerals/precipitates is highly $\mathrm{pH}$ dependent (Gong et al. 2010; Oburger et al. 2011). Therefore, the activation effect of organic acids needs to be further verified.

The activation mechanisms of organic acids on $\mathrm{P}$ also depend on the chemical bonding forms of $\mathrm{P}$ in soils (Khademi et al. 2010). These organic acid anions can mobilize and then release inorganic $\mathrm{P}$ through forming complexes with $\mathrm{Fe}, \mathrm{Al}$, or $\mathrm{Ca}$, blocking $\mathrm{P}$ absorption sites on soil particles (Wei et al. 2010). However, different $P$ fractions are often correlated with each other. Such correlations existing among P fractions often make it difficult to determine the true variable that contributes most to $\mathrm{P}$ activation in soils. In addition, correlation of a $\mathrm{P}$ fraction with the $\mathrm{P}$ activation may not necessarily imply a direct influence of the soil $\mathrm{P}$ fraction on the $\mathrm{P}$ activation. Path analysis, a statistical technique that differentiates between correlation and causation, has been increasingly utilized to define the best criteria for selection in biological and agronomic studies. Path analysis is a standardized partial regression analysis which appears to be helpful in partitioning the correlation coefficients into direct and indirect effects. The direct effect represents the direct contribution of a predictor variable to a response variable. The indirect effect represents the contribution of a predictor variable to a response variable via another predictor variable (Hashimoto et al. 2012). Path analysis has been applied in soil and environmental studies (Hashimoto et al. 2012; He et al. 2018). However, previous studies only reported the activation of $\mathrm{P}$ fractions by organic acids (Wang et al. 2009; Gong et al. 2010; Waithaisong et al. 2015; Clarholm et al. 2015), but it remained unclear how the soil $\mathrm{P}$ fractions interact with each other and what soil P fraction was the most critical variable in characterizing the total activating P.

Black soils (Chernozem) located in northeast China, are one of the most important soil resources for crop growth and play a crucial role in ensuring national food security (Yao et al. 2017). However, a large proportion of agricultural black soils underwent fertility deterioration and soil erosion over the past several decades because of excessive plowing and pesticide and chemical fertilizer treatment (Ding et al. 2016; Wang et al. 2017). In addition, the application of $P$ fertilizer in the form of animal manure and mineral $P$ fertilizer had various negative effects such as soil acidification, metal toxicity, lower P use efficiencies, although improved soil fertility and crop yields
(Zhan et al. 2015; Zhang et al. 2016). Previous research found both tribasic citric acid and the dibasic oxalic acid had induced higher P mobilization than other organic acids among the most commonly produced root and microbial exudates affecting rhizosphere $\mathrm{P}$ availability in soils (Menezes-Blackburn et al. 2016). Simultaneously, inorganic $P\left(P_{i}\right)$ pool from surface soil increased with long-term applications of phosphate fertilizer (Rubaek and Sibbesen 1995). So we hypothesized that applying LMWOAs was an effective practice to improve $P_{i}$ availability. The objectives of this study were (1) to investigate the potential activating capability mechanism of individual $\mathrm{P}_{\mathrm{i}}$ fractions by LMWOAs, (2) to distinguish the acidity effects of protons and complex effects of organic anions via the adjusted $\mathrm{pH}$ in solution, (3) to provide information on the relative contribution of individual activating- $\mathrm{P}_{\mathrm{i}}$ fraction to soil total activating- $\mathrm{P}_{\mathrm{i}}$.

\section{Materials and methods}

\subsection{Study area and sampling}

The study area is located in the Black soil (Mollisol) region of northeast China on Keshan Farm (lat. $48^{\circ} 12^{\prime}-48^{\circ} 23^{\prime} \mathrm{N}$, long. $125^{\circ} 08^{\prime}-125^{\circ} 37^{\prime} \mathrm{E}$ ). The arable soil has a history of being fertilized annually with inorganic $\mathrm{P}$ such as potassium dihydrogen phosphate $\left(\mathrm{KH}_{2} \mathrm{PO}_{4}\right)$ or diammonium phosphate $\left(\mathrm{NH}_{4}\right)_{2} \mathrm{HPO}_{4}$. Soil samples were collected at depth of 0 $20 \mathrm{~cm}$ according to the S-type sampling method under a natural secondary forest of Populus davidiana Dode (Populus davidiana) due to no known history of using external fertilizers, and then mixed in equal amounts, gently crumbled, and sieved through $2 \mathrm{~mm}$ prior to analyses. Soil samples exhibited a silt loam texture with 505,317 , and $178 \mathrm{~g} \mathrm{~kg}^{-1}$ in clay, silt, and sand, respectively; moreover, the samples demonstrated a soil bulk density of $1.17 \mathrm{~g} \mathrm{~cm}^{-3}$, soil $\mathrm{pH}$ of 6.25 , organic matter of $83.8 \mathrm{~g} \mathrm{~kg}^{-1}$, total $\mathrm{P}$ of $0.92 \mathrm{~g} \mathrm{~kg}^{-1}$, available $\mathrm{P}$ of $13.42 \mathrm{mg} \mathrm{kg}^{-1}$, and total $\mathrm{N}$ of $4.89 \mathrm{~g} \mathrm{~kg}^{-1}$.

\subsection{Experimental design}

Soil samples were placed in plastic bags and $\mathrm{P}$ was added at the rate of $200 \mathrm{mg} \mathrm{kg}^{-1}$ soil as $\mathrm{KH}_{2} \mathrm{PO}_{4}$ and incubated for 90 days at $25^{\circ} \mathrm{C}$. The appropriate amount of distilled water was added until $70 \%$ of field capacity was reached. Distilled water was replenished every other day during the incubation in accordance with the gravimetric method to maintain water at initial levels. Four replicates were performed. After incubation, soil samples were mixed in equal amounts, and then air-dried and passed through a 2-mm sieve before use.

To determine the concentration-dependent extraction efficiency of the organic acids on $P_{i}$ and individual $P_{i}$ fractions 
from the black soil, $20 \mathrm{~mL}$ of organic acid solution was added to $1.0 \mathrm{~g}$ of spare soil. Both oxalic and citric acids which were the most common organic acids involved in the release of soil P (Khademi et al. 2010; Menezes-Blackburn et al. 2016), was chosen by considering the rhizosphere value at concentrations of $0,0.5,1.0,1.5$, and $2.5 \mathrm{mmol} \mathrm{L}^{-1}$. The samples were orbitally shaken for $30 \mathrm{~min}$ at $25^{\circ} \mathrm{C}$, centrifuged $(5000 \mathrm{rpm}$, $10 \mathrm{~min}$ ), and finally filtered through $0.45-\mu \mathrm{m}$ membrane filters. The $\mathrm{P}$ in solution was analyzed calorimetrically using the ascorbic acid-molybdophosphate blue method. The amount of total activating- $P_{i}$ was estimated as the difference between the total amount of $P_{i}$ extracted with and without organic acid. Subsequently, the soil extracted by the organic acids was washed with alcohol to remove residual low-molecularweight organic acids between soil particles (Liu et al. 2009), and then used to determine the $\mathrm{P}$ fractions by sequential extractions as described by Hedley et al. (1982) and modified by Tiessen and Moir (1993) (Sui et al. 1999). Briefly, $1 \mathrm{~g}$ of soil was successively extracted using $25 \mathrm{~mL}$ of deionized water, $0.5 \mathrm{~mol} \mathrm{~L}^{-1} \mathrm{NaHCO}_{3}\left(\mathrm{pH}\right.$ 8.5) (labile $\mathrm{P}_{\mathrm{i}}$ adsorbed on the soil surface), $0.1 \mathrm{~mol} \mathrm{~L}^{-1} \mathrm{NaOH}$ (moderately labile $\mathrm{P}_{\mathrm{i}}$ held more strongly by chemisorption to surfaces of $\mathrm{Al}$ and $\mathrm{Fe}$ oxides), $1 \mathrm{~mol} \mathrm{~L}^{-1} \mathrm{HCl}$ ( $\mathrm{P}$ associated with calcium and derived from primary mineral apatite) and $\mathrm{H}_{2} \mathrm{SO}_{4}+\mathrm{HClO}_{4}$ (residual P-nonlabile; stable organic $\mathrm{P}$ forms and relatively insoluble $\mathrm{P}_{\mathrm{i}}$ forms) for $16 \mathrm{~h}$ each. The activating amount of the individual $P_{i}$ fractions was determined as the difference between the $P$ extracted from the individual $P_{i}$ fractions without and with organic acids (Gong et al. 2010). Four replicates of each treatment were performed and the average values were reported.

To determine the $\mathrm{pH}$ effect on the activation of organic acids, both oxalate at $\mathrm{pH}$ of $2.6-6.0$ and citrate at $\mathrm{pH}$ of $2.8-$
6.0 were selected at concentrations of $2.5 \mathrm{mmol} \mathrm{L}^{-1}$. The $\mathrm{pH}$ values were adjusted by either $0.1 \mathrm{~mol} \mathrm{~L}^{-1} \mathrm{NaOH}$ or $\mathrm{HCl}$. The remaining steps were carried out as described above. The experiment was carried out as described above except for the addition of organic acids to reach the target $\mathrm{pH}$. Four replicates of each treatment were performed and the average values were reported.

\subsection{Statistical analyses}

The analysis of one-way ANOVA and multiple comparisons with LSD test at $P<0.05$ were performed using SPSS 16.0. All the data were homoscedastic and normally distributed. Simple correlation analyses as well as path analyses among soil $\mathrm{P}$ indices were also performed using SPSS 16.0. The correlation analysis was used to analyze the relationship between the total activating- $\mathrm{P}_{\mathrm{i}}$ and $\mathrm{P}_{\mathrm{i}}$ fractions. The path diagram was used to examine the causal path of $P_{i}$ fractions to the total activating- $\mathrm{P}_{\mathrm{i}}$. Direct and indirect effects in the path analysis were derived from (i) multiple linear regressions of $P_{i}$ fractions on the total activating- $P_{i}$ and (ii) simple correlation coefficients between $P_{i}$ fractions. The direct effects of $P_{i}$ fractions on the total activating- $P_{i}$ were termed path coefficients and were standardized partial regression coefficients for each of the soil $P_{i}$ fractions in the multiple linear regression against the total activating- $\mathrm{P}_{\mathrm{i}}$. Indirect effects of $P_{i}$ fractions on the total activating- $P_{i}$ were determined from the product of the simple correlation coefficient between soil $\mathrm{P}_{\mathrm{i}}$ fractions and the path coefficient. The correlation between the total activating- $P_{i}$ and individual $\mathrm{P}_{\mathrm{i}}$ fraction was the sum of the entire path connecting two variables (Hashimoto et al. 2012).
Fig. 1 The amount of total activating- $P_{i}$ induced by LMWOAs at different concentrations

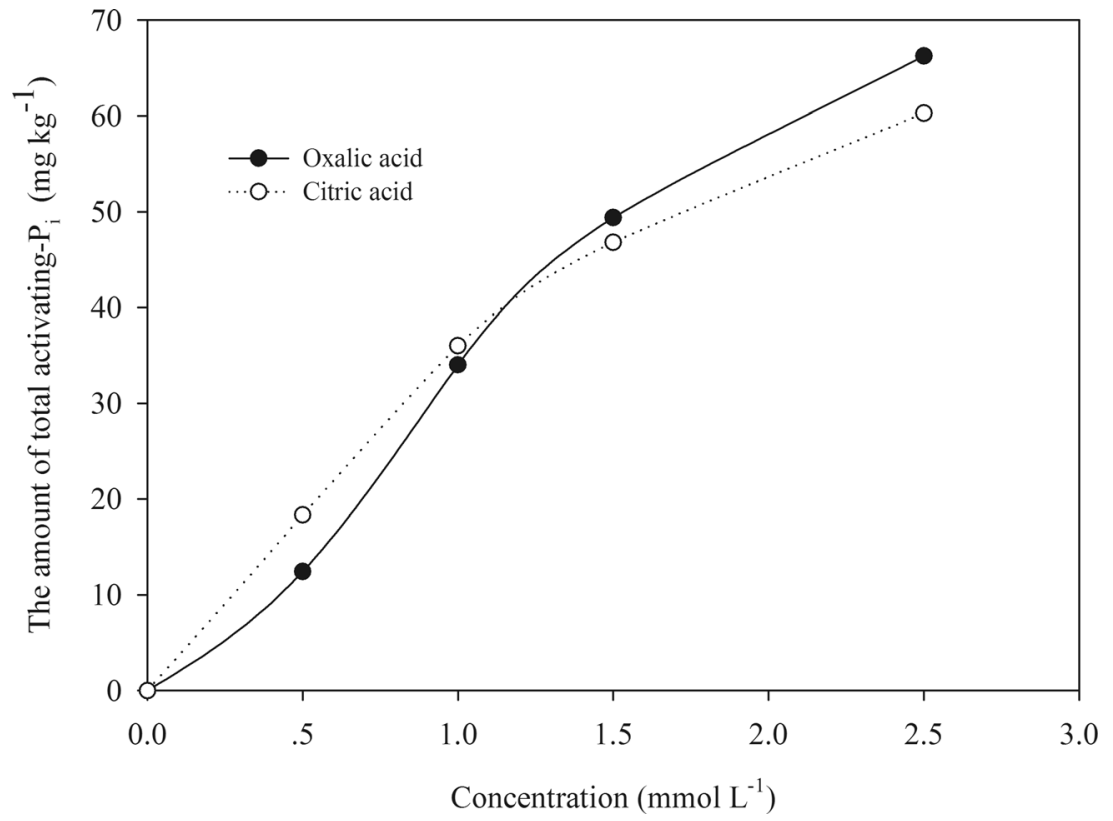




\section{Results}

\subsection{Total $P_{i}$ activation}

The activating capability of both oxalic and citric acids increased significantly with increasing their concentrations $(p<0.05)$, whereas lower concentration of organic acids at $0.5 \mathrm{mmol} \mathrm{L}^{-1}$ could induce the activation of total $\mathrm{P}_{\mathrm{i}}$ (Fig. 1). When their concentrations reached $2.5 \mathrm{mmol} \mathrm{L}^{-1}$, the amounts of total activating- $\mathrm{P}_{\mathrm{i}}$ by oxalic acid was 5.32 times of that at $0.5 \mathrm{mmol} \mathrm{L}^{-1}$ concentration.

The amounts of total activating- $\mathrm{P}_{\mathrm{i}}$ were significantly correlated with the type of organic acids (Fig. 1). When the concentrations of the organic acids were $\leq 1 \mathrm{mmol} \mathrm{L}^{-1}$, oxalic acid exhibited a lower activating capability than citric acid, while oxalic acid was higher in total activating- $\mathrm{P}_{\mathrm{i}}$ when the concentrations were $\geqq 1.5 \mathrm{mmol} \mathrm{L}^{-1}$.

\subsection{Activation capacity of individual soil $P_{i}$ fractions}

The activating amounts of individual $P_{i}$ fractions depended on their individual characteristics and the type and concentration of organic acids (Table 1). Both oxalic and citric acids promoted the activation of soil $\mathrm{NaHCO}_{3}-\mathrm{P}_{\mathrm{i}}, \mathrm{NaOH}-\mathrm{P}_{\mathrm{i}}$ and $\mathrm{HCl}-\mathrm{P}_{\mathrm{i}}$ except activated by $0.5 \mathrm{mmol} \mathrm{L}^{-1}$ organic acids, and the activating capacity tended to increase significantly as their concentrations increased $(p<0.05)$. Table 1 also showed that the amounts of activating- $\mathrm{NaHCO}_{3}-\mathrm{P}_{\mathrm{i}}$ and activating-NaOH- $\mathrm{P}_{\mathrm{i}}$ were higher than other $\mathrm{P}_{\mathrm{i}}$ fractions. In addition, when the same concentrations of organic acids were prepared, oxalic acid was more effective than citric acid in enhancing $P_{i}$ activation from the $\mathrm{NaHCO}_{3}-\mathrm{P}_{\mathrm{i}}$ fraction, while citric acid was more effective in enhancing $\mathrm{P}_{\mathrm{i}}$ activation from the NaOH- $\mathrm{P}_{\mathrm{i}}$ and $\mathrm{HCl}-\mathrm{P}_{\mathrm{i}}$ fractions. For Res-P, no significant difference in the amounts of activating-Res-P was found between with and without the treatments of organic acids (Table 1). This could imply that despite concentrations effects, Res-P was generally not activated easily by organic acids.

\subsection{Activation of total $P_{i}$ by protons and organic anions}

The amounts of total activating- $\mathrm{P}_{\mathrm{i}}$ induced by $2.5 \mathrm{mmol} \mathrm{L}$ organic acids at different $\mathrm{pH}$ levels were studied to distinguish the relative effects of hydrogen protons and organic anions, both of which were components of LMWOAs (Fig. 2). The amount of total activating- $P_{i}$ decreased significantly with increasing $\mathrm{pH}(p<0.05)$, particularly induced by oxalate with the greater relative effect of $\mathrm{pH}$ on the activating capability.

Figure 2 also showed that the $\mathrm{pH}$-dependent effectiveness of organic acids to activate total $\mathrm{P}_{\mathrm{i}}$ was strongly influenced by cations. The oxalate was more effective than citrate at $\mathrm{pH}<$ 3.0, whereas citrate was more effective in terms of total 
Fig. 2 The amount of total activating- $\mathrm{P}_{\mathrm{i}}$ induced by LMWOAs at different $\mathrm{pH}$ levels

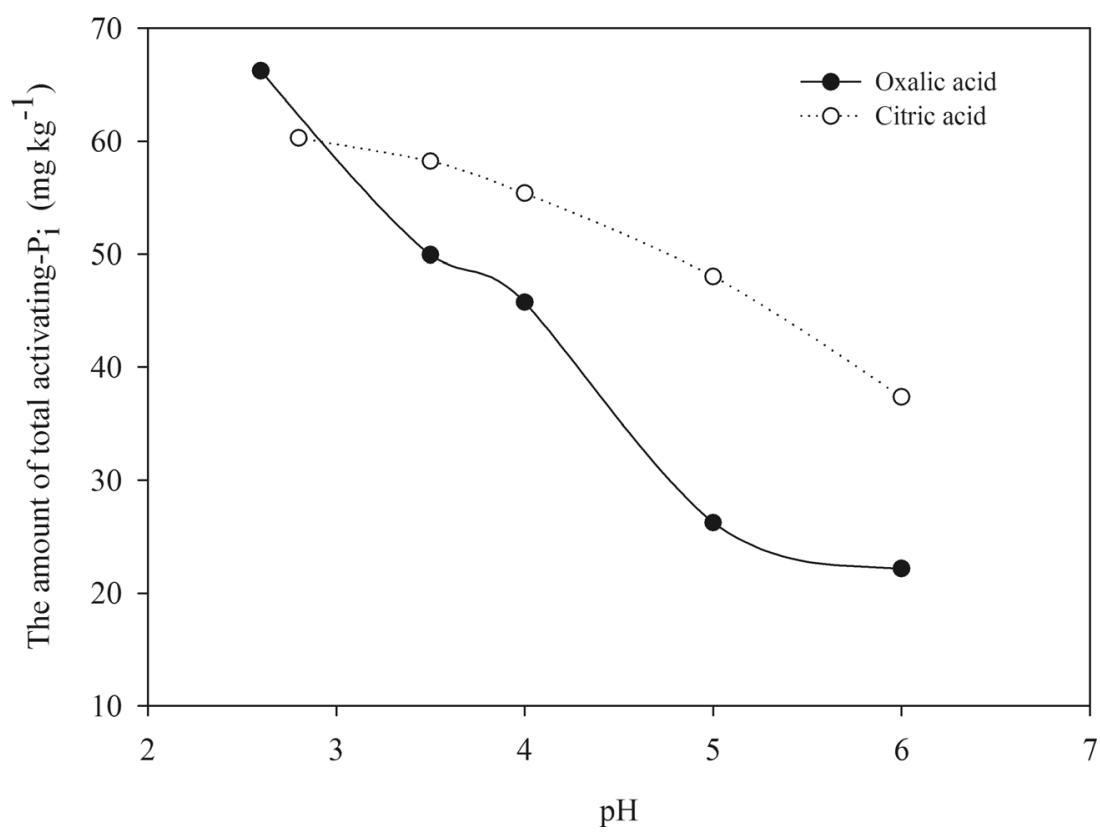

activating- $\mathrm{P}_{\mathrm{i}}$ at $\mathrm{pH} \geq 3.5$, with $1.21,1.83$, and 1.69 times higher than oxalate at $\mathrm{pH} 4.0,5.0$, and 6.0 , respectively.

\subsection{Activation capacity of individual $P_{i}$ fractions by protons and organic anions}

In accordance with the modified Hedley sequential extractions (Table 2), both oxalate and citrate at all tested $\mathrm{pH}$ levels inhibited the activation of $\mathrm{H}_{2} \mathrm{O}-\mathrm{P}_{\mathrm{i}}$, and this degree of inhibition tended to decrease for oxalate but increase for citrate as the $\mathrm{pH}$ increased, while promoted the activation of $\mathrm{NaHCO}_{3}-\mathrm{P}_{\mathrm{i}}, \mathrm{NaOH}-\mathrm{P}_{\mathrm{i}}$, and HCl- $\mathrm{P}_{\mathrm{i}}$ with the exception of oxalate at $\mathrm{pH}$ 6.0. Simultaneously, Table 2 also showed that the activating amounts of $\mathrm{NaHCO}_{3}-\mathrm{P}_{\mathrm{i}}$ and NaOH$-\mathrm{P}_{\mathrm{i}}$ were higher than other $\mathrm{P}_{\mathrm{i}}$ fractions, and tended to decrease significantly as $\mathrm{pH}$ of LMWOAs increased $(p<0.05)$. In addition, the type of organic acid affected the activating amount of individual $\mathrm{P}_{\mathrm{i}}$ fractions. When the same organic acid concentrations were prepared, citrate was more effective than oxalate in activating- $\mathrm{NaHCO}_{3}-\mathrm{P}_{\mathrm{i}}$ except at $\mathrm{pH}$ $<3.0$, activating- $\mathrm{NaOH}-\mathrm{P}_{\mathrm{i}}$, and activating-HCl- $\mathrm{P}_{\mathrm{i}}$ at all tested $\mathrm{pH}$ levels (Table 2). For Res-P, both oxalate and citrate at all tested $\mathrm{pH}$ levels neither promoted nor inhibited the activation of Res-P, although the amounts of activating-Res-P were positive. In contrast, no significant differences were observed in the presence or absence of organic acids at any tested $\mathrm{pH}$ level.

\subsection{Correlation analysis}

The activating amount of total $P_{i}$ was significantly correlated with that of individual $\mathrm{P}_{\mathrm{i}}$ fractions except Res-P (Table 3), and showed the highest correlation with the activating- $\mathrm{NaHCO}_{3}$ $\mathrm{P}_{\mathrm{i}}(r=0.917)$, followed by activating-NaOH- $\mathrm{P}_{\mathrm{i}}(r=0.891)$.
This indicated that the activation of total $\mathrm{P}_{\mathrm{i}}$ was associated more with the activation of $\mathrm{NaHCO}_{3}-\mathrm{P}_{\mathrm{i}}$ and $\mathrm{NaOH}-\mathrm{P}_{\mathrm{i}}$ than that of other $P_{i}$ fractions. Table 3 also showed that different correlations existed between the activation of individual $P_{i}$ fractions, and a stronger correlation was found between the activation of $\mathrm{NaHCO}_{3}-\mathrm{P}_{\mathrm{i}}$ and NaOH-P $\mathrm{P}(r=0.852)$. These correlations among the individual $\mathrm{P}_{\mathrm{i}}$ fractions could be indicative of collinearity among predictor variables for the total activating- $\mathrm{P}_{\mathrm{i}}$. Despite this, such significant collinearity could mask the true causal factors related to the activation of total $\mathrm{P}_{\mathrm{i}}$.

\subsection{Path analysis}

Path analysis was used to analyze the relationship among the activation of individual $\mathrm{P}_{\mathrm{i}}$ fractions, and determine the relative importance of direct and indirect effects on the total activating- $\mathrm{P}_{\mathrm{i}}$. Soil activating- $\mathrm{H}_{2} \mathrm{O}-\mathrm{P}_{\mathrm{i}}$ had a small direct-path coefficient and a large indirect-path coefficient which implied that it mainly affected $\mathrm{P}_{\mathrm{i}}$ activation through an indirect path (Table 4). The activation of $\mathrm{NaHCO}_{3}-\mathrm{P}_{\mathrm{i}}, \mathrm{NaOH}-\mathrm{P}_{\mathrm{i}}$, and $\mathrm{HCl}-$ $\mathrm{P}_{\mathrm{i}}$ directly significantly affected the activation of total $\mathrm{P}_{\mathrm{i}}(p<$ $0.05)$, and the contribution of activating $-\mathrm{NaHCO}_{3}-\mathrm{P}_{\mathrm{i}}$ alone (direct effects) was maximal, followed by $\mathrm{NaOH}-\mathrm{P}_{\mathrm{i}}$ and $\mathrm{HCl}-\mathrm{P}_{\mathrm{i}}$. Moreover, examination of the indirect effects revealed that the indirect-path coefficients of other activating- $P_{i}$ fractions on the total activating- $\mathrm{P}_{\mathrm{i}}$ via activating- $\mathrm{NaHCO}_{3}-\mathrm{P}_{\mathrm{i}}$ were larger than those via other activating- $\mathrm{P}_{i}$ fractions, with the exception of activating-Res-P. For $\mathrm{NaOH}-\mathrm{P}_{\mathrm{i}}$, soil activating$\mathrm{NaOH}-\mathrm{P}_{\mathrm{i}}$ had a large direct and indirect-path coefficient which implied that had direct and indirect effects on $\mathrm{P}_{\mathrm{i}}$ activation (Table 4). In addition, the indirect-path coefficient of activating-NaOH- $\mathrm{P}_{\mathrm{i}}$ via activating- $\mathrm{NaHCO}_{3}-\mathrm{P}_{\mathrm{i}}$ was larger than that 
via other activating- $\mathrm{P}_{\mathrm{i}}$ fractions. With respect to $\mathrm{HCl}-\mathrm{P}_{\mathrm{i}}$, the indirect-path coefficient of activating-HCl- $\mathrm{P}_{\mathrm{i}}$ via activating$\mathrm{NaHCO}_{3}-\mathrm{P}_{\mathrm{i}}$ was larger than that via other activating- $\mathrm{P}_{\mathrm{i}}$ fractions. For Res-P, Table 4 showed that soil activating-Res-P had a small direct-path coefficient and indirect-path coefficient which implied that its contribution was small to $P_{i}$ activation.

\section{Discussion}

Both oxalic and citric acids could solubilize significant amounts of soil $\mathrm{P}_{\mathrm{i}}$, making the nutrient more accessible to plants, and higher concentrations of organic acids always resulted in greater amounts of total activating- $\mathrm{P}_{\mathrm{i}}$ than lower concentrations did. These results agreed with previous studies (Harrold and Tabatabai 2006; Gong et al. 2010; Lv et al. 2015). The concentrations of protons and organic acid anions increased as the organic acid concentrations increased, and the acidification effects of the protons and the complex effects of the organic anions were also subsequently enhanced. This eventually led the improvement of activating capability to $\mathrm{P}_{\mathrm{i}}$. However, Wei et al. (2010) reported that organic acids (maleic, oxalic, and citric acids) at concentrations of $10 \mathrm{mmol} \mathrm{kg}^{-1}$ soil did not enhance the release of $\mathrm{P}_{\mathrm{i}}$ but were effective at mobilizing $\mathrm{P}$ from the soil. In addition, oxalic acid impacted the activating capability less than citric acid did at lower concentrations $\left(\leq 1.0 \mathrm{mmol} \mathrm{L}^{-1}\right)$ from black soil. Our research about the adsorption capacity of low-molecular-weight organic acids from black soil showed that the adsorption amount of oxalic acid was lower than citric acid when the concentration was $\leq 1.0 \mathrm{mmol} \mathrm{L}^{-1}$ (Supplementary material). This indicated that oxalic acid at lower concentrations had a lower ability to activate $\mathrm{P}$ than citric acid. For individual activating- $\mathrm{P}_{\mathrm{i}}$ fractions, the activating amounts tended to increase as the concentration of organic acids increased, except Res-P. Thus, increased amounts or the generally high exudation of oxalate and citrate could benefit the uptake of $\mathrm{P}$ by plants.

The results of the $P_{i}$ release induced by organic acids at different $\mathrm{pH}$ levels showed that the capability of total activating- $\mathrm{P}_{\mathrm{i}}$ tended to decrease as the $\mathrm{pH}$ increased. This might be due to the inhibition of LMWOAs on $\mathrm{P}$ adsorption weakened with increasing $\mathrm{pH}$, and finally changed to promotion of $\mathrm{P}$ adsorption (Wang et al. 2012). Moreover, when the same concentrations of organic acids were added, the concentration of hydrogen protons tended to decline with increasing $\mathrm{pH}$ value. This indicated that the acidization effect weakened. By contrast, the chelation ability was enhanced. Only when the weakened degree of acidization effect was greater than the enhancement of the chelation effect, it was possible that the amount of total activating- $\mathrm{P}_{\mathrm{i}}$ decreased with increasing organic acid $\mathrm{pH}$. This observation indicated that the acidification effect was higher than the chelation ability of LMWOAs to activate $\mathrm{P}_{\mathrm{i}}$. This finding was supported by Gong et al. (2010). The activation of individual $P_{i}$ fractions by organic acid anions at different $\mathrm{pH}$ levels significantly differed. The 
Table 3 Correlation matrix between the activating amounts of total $\mathrm{P}_{\mathrm{i}}$ and individual $\mathrm{P}_{\mathrm{i}}$ fractions

\begin{tabular}{|c|c|c|c|c|c|c|}
\hline & $A$ & $\mathrm{H}_{2} \mathrm{O}-\mathrm{P}_{\mathrm{i}}$ & $\mathrm{NaHCO}_{3}-\mathrm{P}_{\mathrm{i}}$ & $\mathrm{NaOH}-\mathrm{P}_{\mathrm{i}}$ & HCl-P $\mathrm{P}_{\mathrm{i}}$ & Res-P \\
\hline A & 1.000 & $-0.670 * *$ & $0.917 * *$ & $0.891 * *$ & $0.725^{* *}$ & 0.034 \\
\hline $\mathrm{H}_{2} \mathrm{O}-\mathrm{P}_{\mathrm{i}}$ & & 1.000 & $-0.654 * *$ & $-0.765^{* *}$ & $-0.690^{* *}$ & -0.187 \\
\hline $\mathrm{NaHCO}_{3}-\mathrm{P}_{\mathrm{i}}$ & & & 1.000 & $0.852 * *$ & $0.634 * *$ & -0.017 \\
\hline $\mathrm{NaOH}-\mathrm{P}_{\mathrm{i}}$ & & & & 1.000 & $0.662 * *$ & 0.116 \\
\hline HCl-P ${ }_{i}$ & & & & & 1.000 & 0.014 \\
\hline Res-P & & & & & & 1.000 \\
\hline
\end{tabular}

$A$ the amount of total activating- $\mathrm{P}_{\mathrm{i}}, * *$ Significant at $p<0.01$ activating amounts of $\mathrm{NaOH}-\mathrm{P}_{i}, \mathrm{NaHCO}_{3}-\mathrm{P}_{\mathrm{i}}$, and $\mathrm{HCl}-\mathrm{P}_{\mathrm{i}}$ decreased as the $\mathrm{pH}$ increased. This finding supported by Oburger et al. (2011), who demonstrated that acidification might enhance $\mathrm{Fe} / \mathrm{Al}$ mineral solubility, resulting in the liberation of adsorbed $\mathrm{P}$ (proton-promoted dissolution).

According to the correlation matrix and path coefficients, the activation of $\mathrm{NaHCO}_{3}-\mathrm{P}_{\mathrm{i}}, \mathrm{NaOH}-\mathrm{P}_{\mathrm{i}}$ and $\mathrm{HCl}-\mathrm{P}_{\mathrm{i}}$ showed a direct effect and an indirect effect significantly on the activation of total $\mathrm{P}_{\mathrm{i}}(p<0.05)$ among five individual $\mathrm{P}_{\mathrm{i}}$ fractions. Those strongest path coefficients matched the result of the simple correlation analysis that determined the correlation with the total activating- $\mathrm{P}_{\mathrm{i}}$. Among them, the activating amounts of $\mathrm{NaHCO}_{3}$ $\mathrm{P}_{\mathrm{i}}$ and $\mathrm{NaOH}-\mathrm{P}_{\mathrm{i}}$ were greater than those of other $\mathrm{P}_{\mathrm{i}}$ fractions with the different treatments of concentrations and $\mathrm{pH}$ values of oxalic and citric acids, and could constitute a potential $\mathrm{P}$ source for plants. Firstly, LMWOAs could solubilize the orthophosphate ions adsorbed on minerals (Waithaisong et al. 2015), and this might be the main reason for larger contribution of activating- $\mathrm{NaHCO}_{3}-\mathrm{P}_{\mathrm{i}}$ which had the largest direct-path coefficient. However, oxalic acid had a stronger ability than citric acid to compete with P for adsorption sties (Wang et al. 2012), which could be explained why oxalic acid was better than citric acid at activating- $\mathrm{NaHCO}_{3}-\mathrm{P}_{\mathrm{i}}$; Secondly, citrate and oxalate benefitted for the formation of stable 5- or 6-bond ring structures that had trivalent cations such as $\mathrm{Al}^{3+}$ and $\mathrm{Fe}^{3+}$ (Shen et al. 2002; Wang et al. 2012), and this explained the contribution of activating$\mathrm{NaOH}-\mathrm{P}_{i}$ which was moderately labile $\mathrm{P}_{i}$ which held more strongly by chemisorption to the surfaces of $\mathrm{Al}$ and Fe oxides (Wang et al. 2017) for total activating- $\mathrm{P}_{\mathrm{i}}$. However, citric acid had a stronger affinity for trivalent metal ions such as with $\mathrm{Al}^{3+}$ and $\mathrm{Fe}^{3+}$, which were dominant in acidic soils, and might have exhibited more P-solubilizing activity than oxalic acids (Shen et al. 2002). This phenomenon might explain the greater amount of activating- $\mathrm{NaOH}-\mathrm{P}_{\mathrm{i}}$ by citric acid than that by oxalic acid; For $\mathrm{HCl}-\mathrm{P}_{\mathrm{i}}$ which was associated with $\mathrm{Ca}$ and derived from primary mineral apatite (Wang et al. 2017), higher concentrations $\left(\geq 1.0 \mathrm{mmol} \mathrm{L}^{-1}\right.$ ) promoted the activation. Many studies also had indicated that $\mathrm{P}$ release occurred only at relatively high organic acid concentrations and the critical threshold for $\mathrm{P}$ release ranged from 2.5 to $10 \mu \mathrm{mol}$ carboxylate $\mathrm{g}^{-1}$ soil (Oburger et al. 2011). In the case of oxalate, $P$ might also be released from various $\mathrm{Ca}$ phosphate minerals via the formation and precipitation of $\mathrm{Ca}$-oxalate. In contrast, citric acid was much more effective than oxalic acid in the present study, and this finding supported the results of Wang et al. (2009). Khademi et al. (2010) reported that the reaction between $\mathrm{Ca}$ and oxalate was rapid, and consequently, the oxalate-mediated release of $\mathrm{P}$ from the soil was similarly rapid. However, influences on the rate of organic acid reaction time with P-containing minerals and metals in the soil remain unknown and may differ. Therefore, further work is needed to determine whether the reaction time is linked to differences between oxalic and citric acids in activating-HCl- $\mathrm{P}_{\mathrm{i}}$.

\section{Conclusions}

These laboratory experiments clearly demonstrated that both oxalic and citric acids could potentially increase $\mathrm{P}$ activation

Table 4 Direct effects and indirect effects of the activation of individual $\mathrm{P}_{\mathrm{i}}$ fractions on the total activating- $\mathrm{P}_{\mathrm{i}}(n=68)$

\begin{tabular}{|c|c|c|c|c|c|c|c|}
\hline \multirow[t]{2}{*}{ Variable } & \multirow{2}{*}{$\begin{array}{l}\text { Direct-path } \\
\text { coefficient }\end{array}$} & \multicolumn{6}{|c|}{ Indirect-path coefficient } \\
\hline & & $\rightarrow \mathrm{H}_{2} \mathrm{O}-\mathrm{P}_{\mathrm{i}}$ & $\rightarrow \mathrm{NaHCO}_{3}-\mathrm{P}_{\mathrm{i}}$ & $\rightarrow \mathrm{NaOH}-\mathrm{P}_{\mathrm{i}}$ & $\rightarrow \mathrm{HCl}-\mathrm{P}_{\mathrm{i}}$ & $\rightarrow$ Res-P & Total \\
\hline $\mathrm{H}_{2} \mathrm{O}-\mathrm{P}_{\mathrm{i}}$ & 0.134 & & -0.346 & -0.301 & -0.152 & -0.004 & -0.803 \\
\hline $\mathrm{NaHCO}_{3}-\mathrm{P}_{\mathrm{i}}$ & $0.530 * *$ & -0.087 & & 0.335 & 0.140 & -0.000 & 0.388 \\
\hline $\mathrm{NaOH}-\mathrm{P}_{\mathrm{i}}$ & $0.393 * *$ & -0.102 & 0.451 & & 0.146 & 0.002 & 0.497 \\
\hline $\mathrm{HCl}-\mathrm{P}_{\mathrm{i}}$ & $0.220 * *$ & -0.092 & 0.336 & 0.261 & & 0.000 & 0.505 \\
\hline Res-P & 0.019 & -0.025 & -0.009 & 0.046 & 0.003 & & 0.015 \\
\hline
\end{tabular}

**Significant at $p<0.01$ 
from black soils and the activating capability increased as increasing their concentrations. The activating amounts of $\mathrm{NaHCO}_{3}-\mathrm{P}_{\mathrm{i}}$ and $\mathrm{NaOH}-\mathrm{P}_{\mathrm{i}}$ were more than those of other inorganic fractions. As the $\mathrm{pH}$ increased, the activating capability of LMWOAs on the total $\mathrm{P}_{\mathrm{i}}$ and individual $\mathrm{P}_{\mathrm{i}}$ fractions diminished, and the acidification effect was higher than the chelation ability of the LMWOAs. According to the results of the simple correlation and path analyses, activating $\mathrm{NaHCO}_{3}-$ $\mathrm{P}_{\mathrm{i}}$ was the most directly important causal factor for predicting the activation of total $\mathrm{P}_{\mathrm{i}}$, and became a potential source of $\mathrm{P}$ in black soil, followed by NaOH-P $\mathrm{P}_{\mathrm{i}}$ and $\mathrm{HCl}-\mathrm{P}_{\mathrm{i}}$.

Acknowledgements This research was supported by the National Natural Science Foundation of China (No. 31570613) and the National Forestry Industry Public Welfare Projects (No. 201404202).

Open Access This article is distributed under the terms of the Creative Commons Attribution 4.0 International License (http:// creativecommons.org/licenses/by/4.0/), which permits unrestricted use, distribution, and reproduction in any medium, provided you give appropriate credit to the original author(s) and the source, provide a link to the Creative Commons license, and indicate if changes were made.

\section{References}

Bauke SL, Sperber CV, Tamburini F, Siebers N, Amelung W (2017) Biopore effects on phosphorus biogeochemistry in subsoils. Soil Biol Biochem 111:157-165

Cao J, Huang Y, Wang C (2015) Rhizosphere interactions between earthworms (Eisenia fetida) and arbuscular mycorrhizal fungus (Funneliformis mosseae) promote utilization efficiency of phytate phosphorus in maize. Appl Soil Ecol 94:30-39

Clarholm M, Skyllberg U, Rosling A (2015) Organic acid induced release of nutrients from metal-stabilized soil organic matter- the unbutton model. Soil Biol Biochem 84:168-176

Ding J, Jiang X, Ma M, Zhou B, Guan D, Zhao B, Cao F, Li L, Li J (2016) Effect of 35 years inorganic fertilizer and manure amendment on structure of bacterial and archaeal communities in black soil of Northeast China. Appl Soil Ecol 105:187-195

Duminda DMS, Kumaragamage D, Indraratne SP, Flaten D (2017) Fertilizer-induced phosphorus dynamics in alkaline calcareous soils as influenced by soil chemical properties. Can J Soil Sci 97:159-170

Fischer P, Pöthig R, Venohr M (2017) The degree of phosphorus saturation of agricultural soils in Germany: current and future risk of diffuse P loss and implications for soil P management in Europe. Sci Total Environ 599-600:1130-1139

Gong S, Wang X, Zhang T, Li Q, Zhou J (2010) Release of inorganic phosphorus from red soils induced by low molecular weight organic acids. Acta Pedol Sin 47:692-697 (in Chinese)

Harrold SA, Tabatabai MA (2006) Release of inorganic phosphorus from soils by low-molecular-weight organic acids. Commun Soil Sci Plan 37:1233-1245

Hashimoto Y, Kang J, Matsuyama N, Saigusa M (2012) Path analysis of phosphorus retention capacity in allophanic and non-allophanic andisols. Soil Sci Soc Am J 76:441-448

He J, Su D, Lv S, Diao Z, Bu H, Wo Q (2018) Analysis of factors controlling soil phosphorus loss with surface runoff in huihe national nature reserve by principal component and path analysis methods. Environ Sci Pollut Res Int 25:2320-2330
Hedley MJ, White RE, Nye PH (1982) Plant-induced changes in the rhizosphere of rape (Brassica napus var. Emerald) seedlings. Changes in L value, soil phosphate fractions and phosphatase activity. New Phytol 91:45-56

Iyamuremye F, Dick RP (1996) Organic amendments and phosphorus sorption by soils. Adv Agron 56:139-185

Khademi Z, Jones DL, Malakouti MJ, Asadi F (2010) Organic acids differ in enhancing phosphorus uptake by Triticum aestivum L.effects of rhizosphere concentration and counterion. Plant Soil 334: $151-159$

Liu L, Liang CH, Wang Q, Du LY, Wu YM, Han W (2009) Effects of low-molecular-weight organic acids on soil phosphorus release. Plant Nutr Fertil Sci 15:593-600 (in Chinese)

Lv YC, Xu G, Sun JN, Brestič M, ŽIvčák M, Shao HB (2015) Phosphorus release from the soils in the yellow river delta: dynamic factors and implications for eco-restoration. Plant Soil Environ 61:339-343

Menezes-Blackburn D, Paredes C, Zhang H, Giles CD, Darch T, Stutter M, George TS, Shand C, Lumsdon D, Cooper P, Wendler R, Brown L, Blackwell M, Wearing C, Haygarth PM (2016) Organic acids regulation of chemical-microbial phosphorus transformations in soils. Environ Sci Technol 50:11521-11531

Oburger E, Jones DL, Wenzel WW (2011) Phosphorus saturation and pH differentially regulate the efficiency of organic acid anion-mediated P solubilization mechanisms in soil. Plant Soil 341:363-382

Rubaek GH, Sibbesen E (1995) Soil phosphorus dynamics in a long-term field experiment at Askov. Biol Fert Soils 20:86-92

Shen H, Yan X, Zhao M, Zheng S, Wang X (2002) Exudation of organic acids in common bean as related to mobilization of aluminum- and iron-bound phosphates. Environ Exp Bot 48:1-9

Strom L, Owen AG, Godbold DL, Jones DL (2005) Organic acid behaviour in a calcareous soil implications for rhizosphere nutrient cycling. Soil Biol Biochem 37:2046-2054

Sui Y, Thompson ML, Shang C (1999) Fractionation of phosphorus in a mollisol amended with biosolids. Soil Sci Soc Am J 63:1174-1180

Tiessen H, Moir JO (1993) Characterization of available P by sequential extraction. In: MR Carter (ed) Soil sampling and methods of analysis. Lewis Publishing, Chelsea, pp 75-86

Waithaisong K, Robin A, Martin A, Clairotte M, Villeneuve M, Plassard C (2015) Quantification of organic P and low-molecular-weight organic acids in ferralsol soil extracts by ion chromatography. Geoderma 257-258:94-101

Wang SQ, Han XZ, Yan J, Li XH, Qiao YF (2009) Effects of low molecular weight organic acids on $\mathrm{P}$ accumulation in soybean (glycine max 1.) and inorganic $P$ form transformation in soil. Chin J Ecol 28: 1550-1554 (in Chinese)

Wang C, Wang Z, Lin L, Tian B, Pei Y (2012) Effect of low molecular weight organic acids on phosphorus adsorption by ferric-alum water treatment residuals. J Hazard Mater 203-204:145-150

Wang J, Ren C, Cheng H, Zou Y, Bughio MA, Li Q (2017) Conversion of rainforest into agroforestry and monoculture plantation in China: consequences for soil phosphorus forms and microbial community. Sci Total Environ 595:769-778

Wei L, Chen C, Xu Z (2010) Citric acid enhances the mobilization of organic phosphorus in subtropical and tropical forest soils. Biol Fert Soils 46:765-769

Yao Q, Liu J, Yu Z, Li Y, Jin J, Liu X, Wang G (2017) Three years of biochar amendment alters soil physiochemical properties and fungal community composition in a black soil of Northeast China. Soil Biol Biochem 110:56-67

Zhan X, Li Z, Zhou B, Zhu P, Zhang S, Xu M (2015) Changes in Olsen phosphorus concentration and its response to phosphorus balance in black soils under different long-term fertilization patterns. PLoS One 10:e0131713 https://doi.org/10.1371/journal.pone.0131713

Zhang S, Jiang L, Liu X, Zhang X, Shicong FU, Lin D (2016) Soil nutrient variance by slope position in a Mollisol farmland area of Northeast China. Chin Geogra Sci 26:508-517 